ISSN: $1979-7362$

\title{
Analisis Ketersediaan Air pada DAS Kelara dalam Mendukung Program Percetakan Sawah Baru di Kabupaten Jeneponto
}

\author{
Analysis of Water Availability in Kelara Watershed to Support of New Rice Field Production \\ Program in Jeneponto Regency
}

Samsuar, Departemen Teknologi Pertanian, Universitas Hasanuddin, Makassar

Muh. Tahir Sapsal, Departemen Teknologi Pertanian, Universitas Hasanuddin, Makassar

Email: Samsuar_sil@yahoo.com

\begin{abstract}
ABSTRAK
Upaya pemerintah dalam mendukung pencapaian swasembada pangan khususnya untuk komoditi beras, diturunkan melalui program ekstensifikasi lahan dalam bentuk percetakan sawah baru. Namun program tersebut tidak diiringi dengan analisis ketersediaan air untuk memenuhi kebutuhan air pertanian pada daerah percetakan sawah baru. Penelitian ini bertujuan untuk menganalisis ketersediaan air pada DAS Kelara dalam upaya pemenuhan kebutuhan air pada areal pertanian khususnya pada daerah percetakan sawah baru. Selain itu, penelitian ini dapat memberikan gambaran pola tanam yang sesuai pada DAS Kelara sesuai dengan ketersediaan air pada DAS. Hasil penelitian menunjukkan bahwa ketersediaan air pada DAS Kelara untuk budidaya padi atau jagung dengan mengandalkan curah hujan, hanya mampu memenuhi kebutuhan air tanaman sekali dalam setahun. Namun, untuk meningkatkan pemanfaatan lahan budidaya, kekurangan air pada DAS Kelara dapat diambil dari sungai Kelara. Hasil analisis ketersediaan air di DAS Kelara, maka direkomndasikan sistem pertanaman yang paling efektif yaitu Padi - Jagung - Bero, dimana awal pertanaman dilakukan di Bulan Desember dan priode bero di bulan Agustus - Oktober
\end{abstract}

\section{Kata kunci: DAS Kelara, percetakan sawah baru, neraca air}

\section{PENDAHULUAN}

Dalam upaya untuk pencapaian swasembada pangan khususnya komoditi beras, pemerintah Republik Indonesia mengeluarkan program ekstensifikasi lahan dalan bentuk pencetakan sawah baru yang dilakukan di beberapa provinsi di Indonesia. Provinsi Sulawesi Selatan merupakan salah satu daerah yang mengikuti program tersebut dengan target percetakan sawah baru seluas 10.000 ha yang dilakukan di beberapa kabupaten pada tahun 2016. Kabupaten Jeneponto merupakan salah satu wilayah yang mendapatkan program percetakan sawah dengan total luas mencapai 2379 ha.
Lokasi percetakan sawah di kabupaten Jeneponto tersebar di empat kecamatan yaitu di Kecamatan Bangkala Barat seluas 1963 ha, Kecamatan Rumbia 99 ha, Kecamatan Taroang 58 ha dan KecamatanTuratea 259 ha.

Kebutuhan air akan terus meningkat sejalan dengan adanya pertumbuhan penduduk, industry dan dunia usaha. Hal tersebut disebabkan oleh peningkatan kebutuhan air pada berbagai sektor baik itu domestic, industri, pertanian maupun sebagai sumber energi. Ketersediaan air pada saat ini mungkin masih memenuhi untuk berbagai keperluan diatas, namun, dimasa yang 
akan datang peluang terjadinya krisis air terus meningkat.

$$
\text { Pengelolaan DAS yang kurang }
$$
tepat tentunya dapat menyebabkan terjadinya ketidakseimbangan antara ketersediaan air pada DAS yang cenderung terus menurun dan kebutuhan air yang cenderung meningkat. Perlu adanya suatu upaya pengelolaan DAS secara terpadu yang terintegrasi dari hulu ke hilir. Upaya untuk mempertahankan air di hulu tentunya dapat menjamin ketersediaan air dimasa yang akan datang.

DAS Kelara merupakan salah satu daerah aliran sungai yang terdapat di Kabupaten Jeneponto, dimana pada wilayah DAS tersebut masuk kedalam program percetakan sawah baru. Konversi lahan menjadi lahan pertanian (khususnya sawah) yang terdapat di DAS Kelara menyebabkan terjadinya perubahan kondisi kawasan catchmen area dan dapat menyebabkan terjadinya aliran permukaan. Hal tersebut tentunya akan berpengaruh terhadap kondisi debit air sungai pada DAS tersebut.

Analisis debit sungai Kelara dilakukan dengan menganalisis data-data spasial dan diolah dengan berbasis GIS. Analisis debit air dengan menggunakan data-data berbasis spasial telah banyak dilakukan. Aplikasi SWAT (Soil Water Assessment Tools) merupakan salah satu aplikasi yang dapat menganalisis debit aliran berbasis GIS. Aplikasi tersebut dapat terintegrasi langsung dengan software GIS yaitu ArcGis yang lebih dikenal dengan nama ArcSwat. Aplikasi tersebut dapat menghitung besarnya debit dari suatu aliran sungai, sedimentasi, transpor bahan kimia dari lahan pertanian dan kegunaan lainnya dalam pengelolaan suatu DAS pada periode waktu tertentu.

\section{Tujuan dan Sasaran Penelitian Tujuan Penelitian}

a. Menganalisis ketersediaan air di Kabupaten Jeneponto dalam mendukung program percetakan sawah baru

b. Menganalisis kebutuhan air tanaman dan kebutuhan air irigasi pada lokasi percetakan sawah baru di Kabupaten Jeneponto

c. Memberikan rekomendasi sistem pola tanam pada lahan percetakan sawah baru di Kabupaten Jeneponto

\section{Sasaran Penelitian}

Sasaran dari penelitian ini adalah tersediaanya data neraca air pada lokasi percetakan sawah baru di Kabupaten Jeneponto yang dapat dijadikan sebagai acuan dalam penentuan pola tanam petani. Selain itu, hasil penelitian ini diharapkan mampu memberikan gambaran kondisi ketersediaan air pada lokasi percetakan sawah baru pada masa yang akan datang sehingga dapat dilakukan upaya-upaya untuk mempertahankan ketersediaan air di masa yang akan datang.

\section{BAHAN DAN METODE}

\section{Waktu dan Tempat}

Penelitian ini dilakukan selama 4 bulan sejak bulan Agustus - November 2017. Penelitian dilaksanakan pada kawasan DAS Kelara, yang secara administrative masuk dalam wilayah administrasi Kabupaten Jeneponto, Provinsi Sulawesi Selatan. Das Kelara terletak pada koordinat $119^{\circ} 29^{\prime} 12^{\prime \prime}$ $119^{\circ} 37^{\prime} 58^{\prime \prime}$ BT dan 5 28' 3" - 5 33' 47" LS dengan total luas $39,125.06$ ha. 


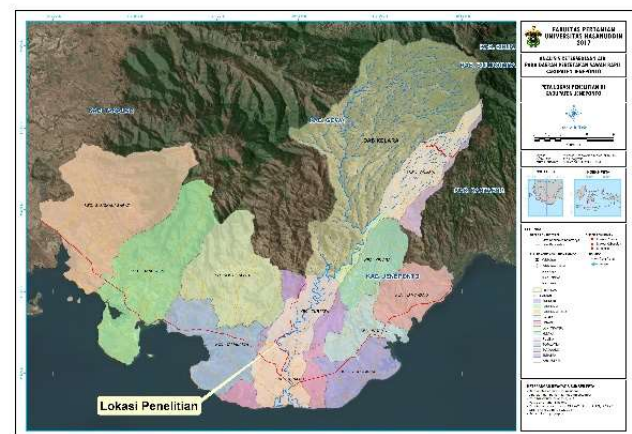

Gambar 1. Lokasi Penelitian

\section{Alat dan Bahan}

Peralatan yang digunakan meliputi seperangkat komputer yang dilengkapi dengan aplikasi ArcSwat, Map Source dan ArcGis. Peralatan pengukuran lapangan meliputi, GPS, Echosounder, Currentmeter, pita ukur, ring sampel dan tali tambang.

Pengumpulan data penelitian meliputi data iklim dan curah hujan harian pada DAS Kelara 10 tahun terakhir, debit dan ketinggian air sungai Kelara, jenis tanah, Digital Elevation Model (DEM) DAS Kelara dengan resolusi $30 \times 30 \mathrm{~m}$, citra landsat, penggunaan lahan pada DAS Kelara dan kebutuhan air pertanian dalam wilayah DAS Kelara.

\section{Metode Penelitian}

Metode penelitian dibagi kedalam 4 tahapan yaitu: 1. Pengumpulan data, 2. Pengolahan data input, 3. Analisis neraca air di DAS Kelara, dan 4. Penyajian data.

Tahap pengumpulan data dilakukan dengan mengumpulkan data dari instansi terkait. Data yang digunakan adalah, DEM, data klimatologi, tutupan lahan, jenis tanah serta kondisi biofisik DAS. Tahapan selanjutnya yaitu pengolahan data input agar sesuai dengan masukan input pada ArcSwat. Tahahapan simulasi dilakukan dengan melakukan perubahan penggunaan lahan pada das khususnya lahan-lahan yang masuk dalam program percetakan sawah baru selanjutnya melihat perubahan debit air di outlet das. Tahapan akhir yaitu melakukan kalibrasi dan validasi terhadap hasilm simulasi dan disajikan dalam plot perubahan lahan terhadap debit pada DAS Kelara.

Dalam mendukung data validasi dan kalibrasi hasil simulasi dilakukan pengukuran langsung dilapangan yang meliputi pengukuran debit sungai Kelara. Dalam pengukuran debit, terlebih dahulu dilakukan pengukuran profil sungai Kelara. Pengukuran kecepatan aliran dilakukan dengan cara membagi penampang melintang saluran setiap meter dan titik pengukuran kecepatan berada pada dua titik yakni pada $0.2 \mathrm{~d}$ dan $0.8 \mathrm{~d}$ dari permukaan air (Chow VT 1989). Selanjutnya dilakukan pembuatan rating curve sungai Kelara dengan menggunakan fungsi spline cubic interpolation yang dikembangkan oleh Setiawan et al, 1997.

Kalibrasi data debit sungai Kelara dilakukan agar hasil simulasi mendekati hasil pengukuran dilapangan. Perbandingan output debit hasil simulasi SWAT dengan debit hasil observasi outlet di lapangan dilakukan dengan menggunakan SWAT Plot dan Graph (George 2008). Analisis dilakukan dengan menggunakan koefisien determinasi $\left(\mathrm{R}^{2}\right)$ dan Nash-Sutcliffe Index (NSI) sebagai berikut:

$$
R^{2}=\left(\frac{\sum_{i=1}^{n}\left(Q_{o, i}-\bar{Q}_{o}\right)\left(Q_{s, i}-\bar{Q}_{s}\right)}{\sqrt{\sum_{i=1}^{n}\left(Q_{o, i}-\bar{Q}_{o}\right)^{2}} \sum_{i=1}^{n}\left(Q_{s}-\bar{Q}_{s}\right)^{2}}\right)^{2}
$$




$$
N S I=1.0-\left(\frac{\sum_{i=1}^{n}\left(Q_{o, i}-\bar{Q}_{S}\right)^{2}}{\sqrt{\sum_{i=1}^{n}\left(Q_{o, i}-\bar{Q}_{o}\right)^{2}}}\right)
$$

dimana:

$\mathrm{Q}_{\mathrm{o}, \mathrm{i}}=$ debit pengukuran di lapangan $\left(\mathrm{m}^{3} / \mathrm{s}\right)$

$\mathrm{Q}_{\mathrm{s}}=$ debit simulasi $\left(\mathrm{m}^{3} / \mathrm{s}\right)$

$\mathrm{Q}_{\mathrm{o}}=$ debit rata-rata dilapangan $\left(\mathrm{m}^{3} / \mathrm{s}\right)$

$\mathrm{Q}_{\mathrm{s}}=$ debit rata-rata simulasi $\left(\mathrm{m}^{3} / \mathrm{s}\right)$

Kategori simulasi berdasarkan nilai NSI adalah sebagai berikut:

- Layak jika NSI > 0.75

- Memuaskan jika $0.75<$ NSI $<0.36$

- Kurang memuaskan jika NSI < 0.36

Jika hasil kalibrasi diperoleh nilai yang memuaskan atau layak, maka model SWAT dapat digunakan dalam simulasi untuk berbagai kondisi pada DAS Kelara.

\section{HASIL DAN PEMBAHASAN}

\section{Gambaran umum wilayah penelitian}

Analisis ketersediaan air pada penelitian ini dilakukan pada DAS Kelara dimana DAS tersebut melalui masuk kedalam wilayah administrasi Kecamatan Rumbia dan bagian hulu masuk dalam wilayah Kabupaten Gowa. Lokasi percetakan sawah baru yang terdapat di DAS Kelara pada umumnya berasal dari konversi lahan yang dahulunya merupakan kebun masyarakat. Sumber air untuk pertanian dapat diperoleh dari sungai yang tersebar merata di sepanjang DAS Kelara.

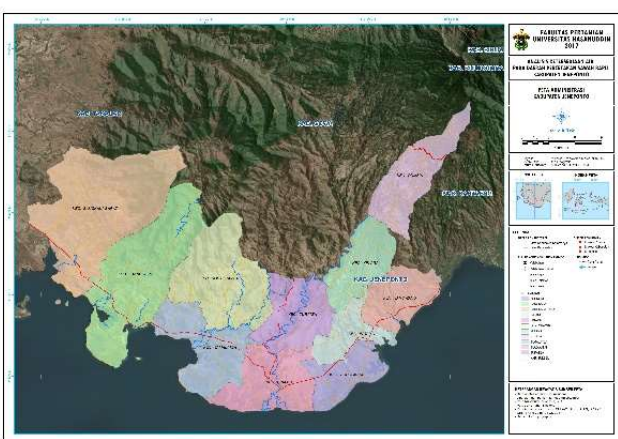

Gambar 2. Peta administrasi Kab. Jeneponto

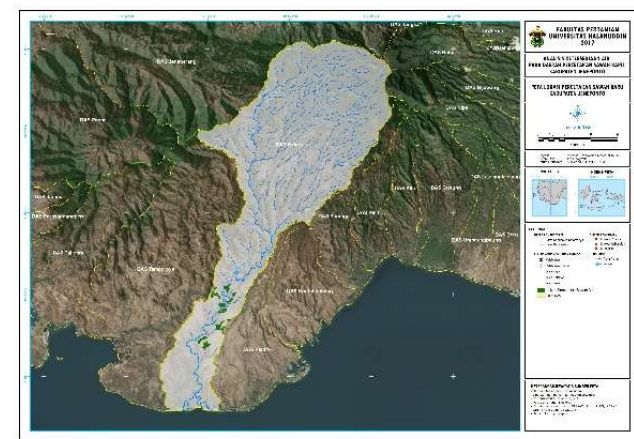

Gambar 3. Lokasi Percetakan Sawah Baru pada DAS Kelara

\section{Kondisi Iklim DAS Kelara}

Data Iklim DAS Kelara diperoleh dari stasiun iklim Gantinga di Kabupaten Jeneponto. Curah hujan di DAS Kelara hanya sekitar $1189 \mathrm{~mm}$ per tahun. Hal ini menunjukkan bahwa DAS Kelara termasuk wilayah kering dimana terdapat 6 bulan tanpa terjadi hujan. Berdasarkan klasifikasi iklim Oldeman, DAS Kelara memiliki 5 tipe iklim yaitu tipe B2, C2 dan C3 pada wilayah hulu (Kabupaten Gowa) dimana tipe iklim ini termasuk tipe iklim basah (bulan basah 6-9 bulan dan bulan kering 2-5 bulan). Untuk wilayah transisi (Kabupaten Jeneponto) dari DAS Kelara masuk dalam tipe iklim D3 dimana bulan basah hanya terjadi 3-4 bulan. Sedangkan hilir dari DAS Kelara 
masuk dalam kategori iklim D4 dimana bulan kering yang terjadi diatas 6 bulan.

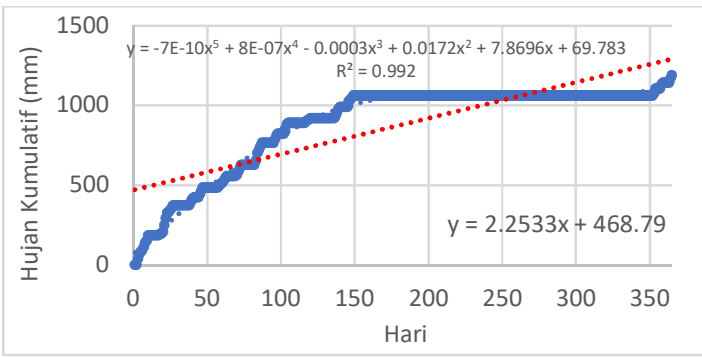

Gambar 4. Pola Hujan Kumulatif di

DAS Kelara Tahun 2015

\section{Jenis Tanah}

Jenis tanah yang terdapat pada DAS Kelara hanya dua jenis yaitu tanah Litosol dan tanah mediteran. Pada bagian hulu DAS hanya ditemukan jenis tanah Litosol. Jenis tanah litosol dengan bahan induk tufa dan batuan vulkanik intermadite, bercirikan warna merah hingga kuning. Jenis tanah ini mempunyai kandungan bahan organik sedang dan bersifat asam. Jenis tanah tersebut berasal dari proses meletusnya gunung berapi dan juga sedimen keras yang mengalami pelapukan tidak sempurna.

Jenis tanah yang terdapat pada DAS Kelara terdapat empat jenis yaitu tanah andosol, grumosol, litosol dan tanah mediteran. Pada bagian hulu DAS hanya ditemukan jenis tanah andosol dan litosol. Jenis tanah litosol dengan bahan induk tufa dan batuan vulkanik intermadite, bercirikan warna merah hingga kuning. Jenis tanah ini mempunyai kandungan bahan organik sedang dan bersifat asam. Jenis tanah tersebut berasal dari proses meletusnya gunung berapi dan juga sedimen keras yang mengalami pelapukan tidak sempurna.
Jenis tanah selanjutnya yang ditemukan yaitu jenis tanah mediteran dengan luasan yang cukup besar dan mendominasi daerah transisi dari DAS. Tanah mediteran merupakan hasil pelapukan dari batuan kapur dan batuan sedimen yang mempunyai warna antara merah sampai kecoklatan. Tanah mediteran termasuk dalam kategori tanah pertanian yang subur pada daerah berkapur. Sedangkan pada daerah hilir ditemukan jenis tanah grumosol. Jenis tanah tersebut masuk dalam kategori tanah kurang subur karena tidak ada aktivitas organik yang terjadi. Tanah tersebut terbentuk dari batuan induk kapur yang bersifat basa sehingga menyerap semua unsur hara pada tanah

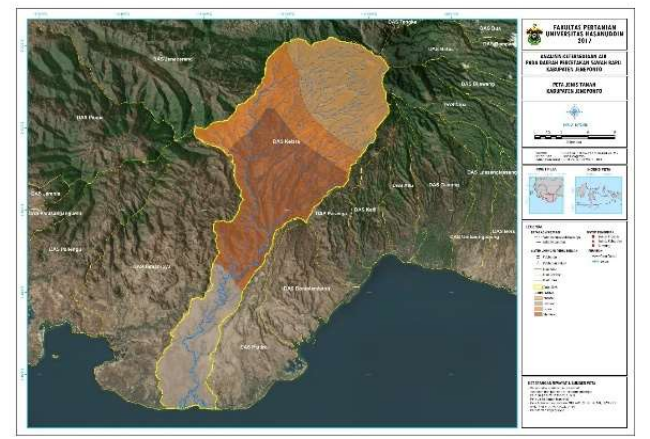

Gambar 5. Jenis Tanah pada DAS Kelara

\section{Penggunaan Lahan}

Penggunaan lahan pada DAS Kelara secara umum terdiri dari hutan, kebun campuran, pertanian lahan kering, semak, sawah dan tambak. Faktor penutupan lahan memberikan pengaruh yang cukup signifikan dalam proses penyimpanan air dalam tanah. Besarnya jumlah air yang masuk kedalam tanah dan yang mengalir melalui aliran permukaan sangat ditentukan oleh tutupan lahan pada daerah tersebut. Tutupan lahan yang dominan di DAS Kelara yaitu pertanian 
lahan kering bercampur semak dimana tutupan lahan tersebut mencapai $67 \%$ dari total luas DAS.

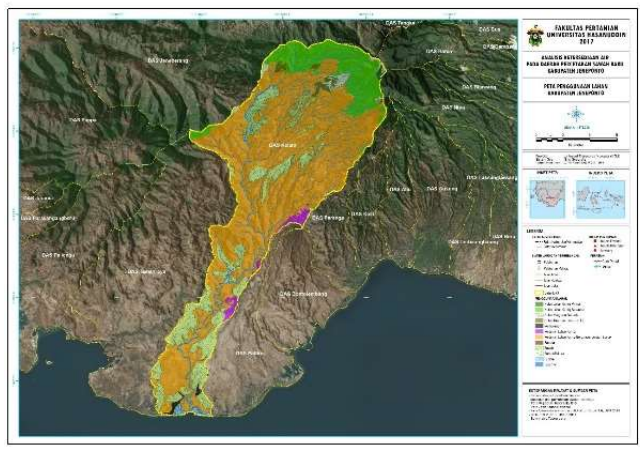

Gambar 6. Penggunaan Lahan pada DAS Kelara

\section{Perhitungan Debit Sungai Kelara}

Pengukuran profil sungai Kelara dilakuakan di hilir sungai yang terletak di Kecamatan Binamu. Hasil pengukuran profil sungai Kelara didapatkan bahwa kedalaman maksimum pada saat pengukuran yaitu $163 \mathrm{~cm}$ dengan total luas penampang sungai $54.21 \mathrm{~m}^{2}$. Kecepatan aliran pada saat pengukuran berkisar antara $0.6-1.63 \mathrm{~m} / \mathrm{s}$. Kecepatan aliran yang tidak merata selama pengukuran disebabkan oleh terdapatnya perahu nelayan disekitar sungai dan tanaman serta sampah di sekitar sungai. Hal ini terjadi karena lokasi pengukuran merupakan kawasan pemukiman dimana aktivitas masyarakat banyak dilakukan.

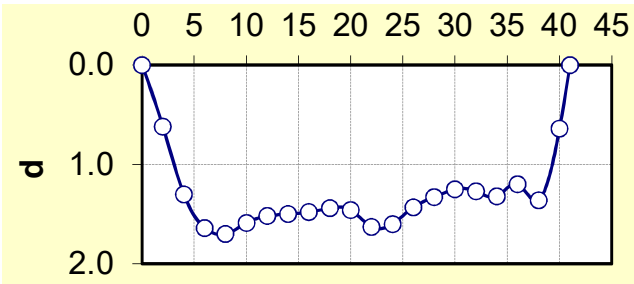

Gambar 7. Profil Sungai Kelara pada saat pengukuran

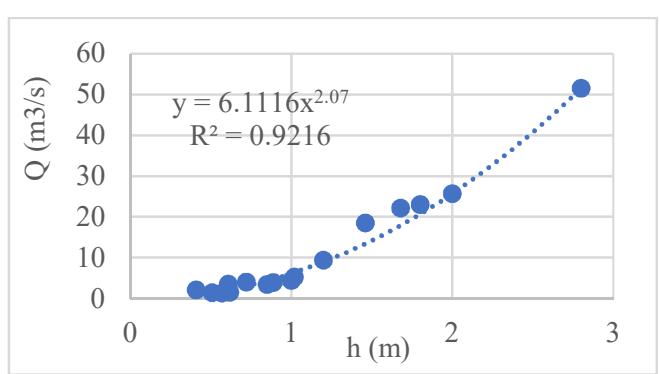

Gambar 8. Rating Curve Sungai Kelara

\section{Ketersediaan Air pada DAS Kelara}

Ketersediaan air di DAS Kelara sangat tergantung dari curah hujan yang turun di wilayah DAS. Perhitungan curah hujan dilakukan dengan menggunakan data curah hujan yang diperoleh dari 7 stasiun penakar hujan yang berada di sekitar DAS Kelara. Data curah hujan yang digunakan sebanyak 10 tahun. Data curah hujan kemudian dihubungkan dengan data debit air di sungai Kelara yang diperoleh dari Balai Besar Wilayah Sungai Jeneberang Walanae. Data curah hujan dan debit sungai kelara disajikan pada Gambar 9

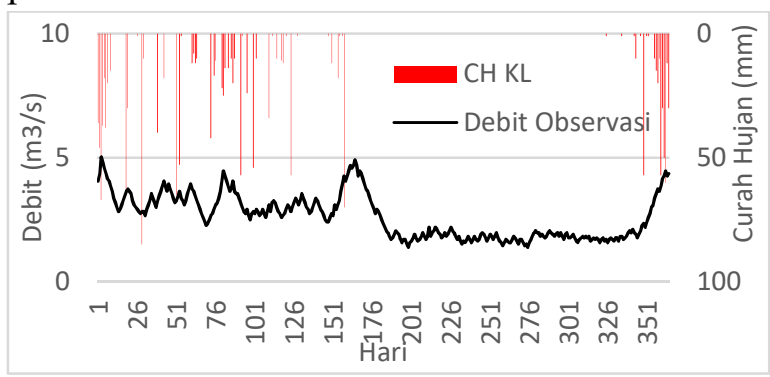

Gambar 9. Curah hujan dan debit DAS

$$
\text { Kelara }
$$

Ketersediaan air di DAS Kelara sangat tergantung dari jumlah air yang jatuh di DAS Kelara. Data curah hujan yang digunakan adalah data curah hujan 11 tahun terakhir (2006-2016) yang kemudian dianalisis untuk mendapatkan curah hujan efektif. Curah hujan tahunan di DAS Kelara sangat bervariasi antara 1587 - $4816 \mathrm{~mm} /$ tahun. Curah hujan 
terredah terjadi pada tahun 2009 dan yang tertinggi terjadi pada tahun 2010. Hasil penentuan curah hujan efektif dengan rumus Harza, maka diperoleh $\mathrm{P}_{\text {ef }}$ di DAS Kelara yaitu $1660 \mathrm{~mm} /$ tahun dimana curah hujan tertinggi terjadi di bulan Januari dan terjadi kekeringan (tidak ada hujan) di bulan Juli - November.

Debit sungai kelara diperoleh dari stasiun klimatologi di desa Likupande, Kecamatan Kelara. Data debit harian sungai kelara diperoleh dari data ketinggian air sungai yang dipantau tiap hari. Untuk memperoleh data debit makan dilakukan pengukuran kecepatan air disungai agar didapatkan hubungan antara ketinggian air dengan debit sungai Kelara. Debit andalan sungai Kelara diperoleh dengan menggunakan persamaan Weibul. Debit sungai inilah yang kemudian diharapkan mampu menyuplai air ke lahan pertanian ketika curah hujan efektif tidak lagi mencukupi. Hasil perhitungan menunjukkan debit sungai Kelara bervariasi antara 1.71 $3.77 \mathrm{~m}^{3} / \mathrm{s}$ dimana tinggi air pada titik pengamatan awlr brkisar antara 0.49 $0.91 \mathrm{~m}$.

\section{Kebutuhan Air Tanaman}

Perhitungan kebutuhan air tanaman di Kabupaten Jeneponto dikhususkan pada komoditi padi dan jagung. Pemilihan kedua komiditi ini dilakukan dengan berdasarkan data di lapangan bahwa kedua komoditi inilah yang banyak dibudidayakan oleh petani. Kebutuhan air tanaman padi tentunya lebih banyak daripada jagung. Hasil perhitungan menunjukkan bahwa kebutuhan air tanaman padi berkisar antara $3.52-5.47 \mathrm{~mm} /$ hari sedangkan jagung berkisar antara $2.36-3.66$ $\mathrm{mm} /$ tahun. Kebutuhan air tertinggi terjadi pada bulan september dimana tidak ada hujan yang turun di wilayah DAS Kelara dan intensitas penyinaran matahari cukup tinggi. Kebutuhan air tanaman padi dan jagung sepanjang tahun disajikan pada Gambar 10.

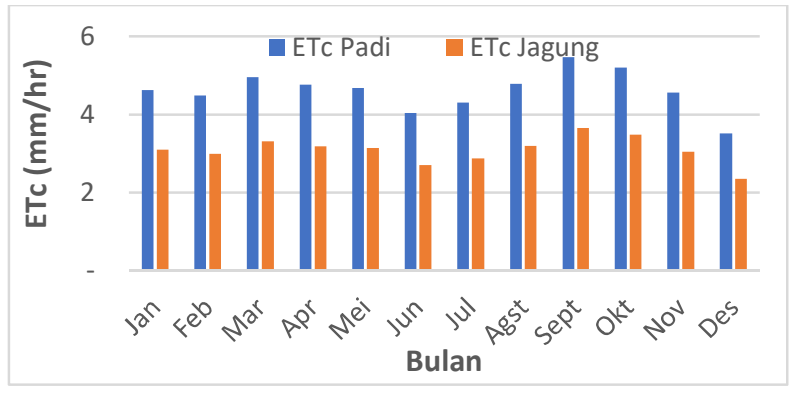

Gambar 10. Kebutuhan air tanaman padi dan jagung di DAS Kelara

Hasil perhitungan neraca air untuk budidaya tanaman Padi dan Jagung menunjukkan bahwa, akan terjadi kekurangah air untuk budidaya kedua tanaman tersebut khususnya di bulan Juli - November. Jika hanya mengandalkan curah hujan, maka tanaman padi hanya dapat dibudidayakan pada bulan Desember - Maret, dan priode selanjutnya dapat diusahakan tanaman Jagung. Pada bulan Mei, budidaya tanaman padi akan mengalami kekurangan air sebesar $1.33 \mathrm{~mm} /$ hari sedangkan pada bulan Juli - November tidak ada lagi curah hujan yang dapat dimanfaatkan untuk budidaya tanaman padi. Sedangkan untuk tanaman jagung masih dapat diusahakan di bulan April Juni, karena kebutuhan air masih lebih rendah dibandingkan dengan kebutuhan air tanaman padi. Namun, untuk bulan Juli sampai dengan November, lahanlahan pertanian yang ada di DAS Kelara 
khususnya yang masuk dalam wilayah Kabupaten Jeneponto tidak dapat diusahakan. Analisis neraca air untuk tanaman padi dan jagung dengan mengandalkan curah hujan efektif pada DAS Kelara dapat dilihat pada Gambar 11



Gambar 11. Neraca air tanaman padi dan jagung di DAS Kelara

Kekurangan air untuk budidaya pertanian khususnya tanaman padi dan jagung di DAS Kelara dapat ditutupi dengan memanfaatkan air dari sungai Kelara. Hasil analisis debit air sungai kelara menunjukkan bahwa air sungai akan selalu tersedia sepanjang tahun. Analisis kebutuhan air irigasi dilakukan khusus untuk areal persawahan dimana luas lahan sawah eksisting di DAS Kelara yang terdapat di Kabupaten Jeneponto yaitu 3,037.35 ha. Jika ditambahkan dengan luas areal percetakan sawah baru yang masuk di wilayah DAS Kelara maka total luas lahan persawahan yaitu $3,329.15$ ha. Alaisis kebutuhan air irigasi dilakukan dengan du skenario diatas yaitu yang pertama hanya luas lahan eksisting dan yang kedua lahan eksisting ditambahkan dengan areal percetakan sawah baru. Analisis kebutuhan air irigasi hanya dilakukan pada bulan Mei serta Juli-November dimana di bulanbulan tersebutlah yang terjadi kekurangan air. Hasil analisis neraca air dengan mengandalkan debit air sungai Kelara untuk memenuhi kebutuhan air tanaman menunjukkan bahwa debit air sungai kelara hanya mampu memenuhi kebutuhan air untuk budidaya padi hanya pada bulan Mei baik untuk skenario 1 maupun 2 . Sedangkan untuk budidaya tanaman Jagung, debit air sungai Kelara masih mampu memenuhi kebutuhan air pada bulan Juli, Agustus dan November. Berdasarkan hasil perhitungan neraca air baik yang hanya mengandalkan curah hujan efektif maupun yang ditambahkan dengan debit air sungai Kelara maka sistem pertanamam yang direkomendasikan yaitu pola padi-jagung-bero dimana awal pertanaman dilakukan di bulan Desember. Neraca air irigasi untuk tanaman padi dan Jagung di Das Kelara dapat dilihat pada Gambar 12 dan kemampuan debit sungai Kelara dalam memenuhi kebutuhan air tanaman padi dan jagung di DAS Kelara disajikan pada Tabel 1

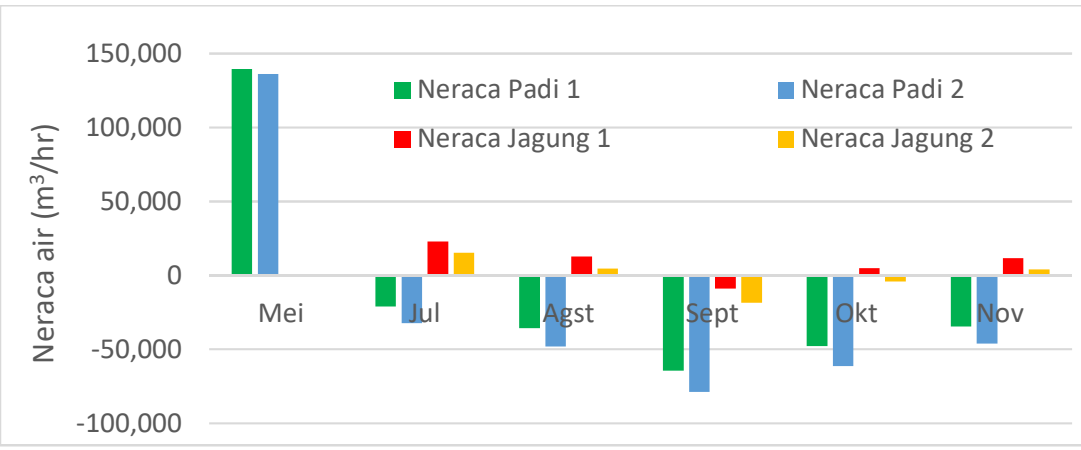

Gambar 12. Neraca air irigasi tanaman padi dan jagung di DAS Kelara 
Tabel 1. Kemampuan debit sungai Kelara dalam memenuhi kebutuhan air tanaman di Kab. Jeneponto

\begin{tabular}{|c|c|c|c|c|c|c|c|c|c|c|}
\hline \multirow{2}{*}{ No. } & \multirow{2}{*}{ Bulan } & \multirow{2}{*}{$\begin{array}{c}\text { Debit } \\
\text { Sungai } \\
\left(\mathrm{m}^{3} / \mathrm{hr}\right)\end{array}$} & \multicolumn{4}{|c|}{ Kekurangan Air (m³/hr) } & \multicolumn{4}{|c|}{ Surplus/Defisit Air $\left(\mathrm{m}^{3} / \mathrm{hr}\right)$} \\
\hline & & & Padi 1 & Padi 2 & Jagung 1 & Jagung 2 & Padi 1 & Padi 2 & Jagung 1 & Jagung 2 \\
\hline 1 & Mei & 180,230 & $-40,688$ & $-44,118$ & & & 139,542 & 136,112 & & \\
\hline 2 & Jul & 111,283 & $-132,220$ & $-143,365$ & $-88,471$ & $-95,928$ & $-20,937$ & $-32,081$ & 22,813 & 15,355 \\
\hline 3 & Ags & 111,283 & $-146,954$ & $-159,341$ & $-98,330$ & $-106,618$ & $-35,671$ & $-48,058$ & 12,954 & 4,665 \\
\hline 4 & Sep & 103,421 & $-167,892$ & $-182,044$ & $-112,340$ & $-121,809$ & $-64,471$ & $-78,623$ & $-8,919$ & $-18,388$ \\
\hline 5 & Okt & 111,888 & $-159,749$ & $-173,215$ & $-106,891$ & $-115,901$ & $-47,861$ & $-61,327$ & 4,997 & $-4,013$ \\
\hline 6 & Nov & 104,026 & $-138,542$ & $-150,220$ & $-92,227$ & $-100,000$ & $-34,516$ & $-46,194$ & 11,799 & 4,025 \\
\hline
\end{tabular}

\section{KESIMPULAN}

1. Ketersediaan air di DAS Kelara untuk budidaya tanaman padi maupun jagung dengan mengandalkan curah hujan hanya mampu mampu memenuhi kebutuhan air padi atau jagung hanya sekali dalam setahun.

2. Pemenuhan kebutuhan air untuk padi dan jagung dapat diambil dari sungai Kelara sehingga dapat meningkatkan ketersediaan air pada DAS Kelara untuk budidaya tanaman padi maupun jagung

3. Hasil alaisis ketersediaan air di DAS Kelara, maka direkomndasikan sistem pertanaman yang paling efektif yaitu Padi - Jagung - Bero, dimana awal pertanaman dilakukan di Bulan Desember dan priode bero di bulan Agustus - Oktober.

\section{DAFTAR PUSTAKA}

Arsyad S. 2006. Konservasi Tanah dan Air. Bogor: IPB Press

Irsyad F. 2011. Analisis Debit Sungai Cidanau dengan Aplikasi SWAT. Institut Pertanian Bogor. Bogor.

Monteith, J.L. 1965. In The state and movement of water in living organisms Evaporation and the Environment.
Swansea: Cambridge University Press. hlm 205-234.

Neitsch SL, Arnold JG, Kiniry JR, Srinivasan R, Williams JR. 2004. Soil and Water Assessment Tool, Input/Output File Documentation Version 2005. Texas: Texas Water Resources Institute.

Neitsch SL, Arnold JG, Kiniry JR, Srinivasan R, Williams JR. 2005. Soil and Water Assessment Tool, Theorical Documentation Version 2005. Grassland Soil and Water Research Laboratory, Agricultural Research Service, Blackland Research CenterTexas Agricultural Experiment Station. USA.

Neitsch SL, Arnold JG, Kiniry JR, Srinivasan R, Williams JR. 2010. Soil and Water Assessment Tool, Input/Output File Documentation Version 2009. Grassland Soil and Water Research Laboratory, Agricultural Research Service, Blackland Research Center-Texas Agricultural Experiment Station. USA.

Setiawan, B.I. 1997. Penerapan Cubic Spline Interpolation dalam Penentuan Debit Sungai. Jurnal Teknik Pertanian 5:1-8. 